\title{
Applicability and cross-cultural validation of the Chinese version of the Warwick-Edinburgh mental well-being scale in patients with chronic heart failure
}

Aishu Dong ${ }^{1}$, Xiuxia Zhang ${ }^{1}$, Haitao Zhou², Siyi Chen², Wei Zhao ${ }^{2}$, Minmin Wu², Junyi Guo ${ }^{3}$ and Wenjian Guo ${ }^{4^{*}}$

\begin{abstract}
Background: The mental well-being of patients with chronic heart failure is likely to influence their health-related quality of life and decrease the utilization of public health resources. This study assessed the mental well-being of patients with chronic heart failure and evaluated the reliability and validity of the Warwick-Edinburgh Mental WellBeing Scale.

Methods: We conducted a cross-sectional survey from July 2016 to July 2017 among 191 patients with chronic heart failure, and examined psychometric properties of the Warwick-Edinburgh Mental Well-Being Scale, such as internal consistency, reliability, test-retest reliability, and factorial validity of the Chinese version of the WarwickEdinburgh Mental Well-Being Scale.

Results: One-dimensional construct validity was demonstrated by confirmatory factor analysis. The psychometric properties of the Chinese version of the Warwick-Edinburgh Mental Well-Being Scale were satisfactory in our sample of patients with chronic heart failure. The internal consistency reliability was .948 and the test-retest reliability .925 . The item-total correlations ranged from .405 to .872 . There was a strong correlation $(r=.79)$ between the Chinese version of the Warwick-Edinburgh Mental Well-Being Scale and the five-item World Health Organization Well-Being Index. The Chinese version of the Warwick-Edinburgh Mental Well-Being Scale appears acceptable for use in patients with chronic heart failure, and we were able to verify its reliability and validity with our sample.

Conclusions: The Chinese version of the Warwick-Edinburgh Mental Well-Being Scale is a reliable quantitative tool for evaluating mental well-being in patients with chronic heart failure in clinical settings, and this has important implications for overall assessments of mental well-being in patients with chronic heart failure.
\end{abstract}

Keywords: Validation, Heart failure, Quality of life, Mental health, Patients, Warwick-Edinburgh mental well-being scale, Mental well-being

\footnotetext{
* Correspondence: 43778521@qq.com

${ }^{4}$ Hematology Department, the Second Affiliated Hospital of Wenzhou

Medical University, College West Road 109, 0577 Wenzhou, Zhejiang,

People's Republic of China

Full list of author information is available at the end of the article
}

(c) The Author(s). 2019 Open Access This article is distributed under the terms of the Creative Commons Attribution 4.0 International License (http://creativecommons.org/licenses/by/4.0/), which permits unrestricted use, distribution, and reproduction in any medium, provided you give appropriate credit to the original author(s) and the source, provide a link to the Creative Commons license, and indicate if changes were made. The Creative Commons Public Domain Dedication waiver (http://creativecommons.org/publicdomain/zero/1.0/) applies to the data made available in this article, unless otherwise stated. 


\section{Background}

According to the definition of the World Health Organization, mental health is "a state of well-being in which every individual realizes his or her own potential, can cope with the normal stresses of life, can work productively and fruitfully, and is able to make a contribution to her or his community" [1]. Nowadays, mental health additionally involves the presence of psychological resources, including both eudemonic and hedonic aspects [2, 3]. It has been found that people with better mental health show lower utilization of public health services in some researches $[4,5]$. Positive mental health with the definition of "the scientific study of those positive strengths and virtues that enable people \& communities to reach optimal levels of health, happiness and well-being" [6], increasingly plays an important role in health-related quality of life, which has gradually been growing interest among people along with economic development, social progress, and the rise in patient-oriented service. It has social consequences and significant health outcomes [7, 8], and it could replace the traditional medical treatment of mental illness [9]. Historically, humans have always been interested in determining the factors that influence their health, well-being, and happiness. A study reported that "the term positive mental health is often used in both policy and academic literature, interchangeably with the term mental well-being" [10]. Mental well-being is a complex construct, covering both affect and psychological functioning with two distinct perspectives: the hedonic perspective, which focuses on the subjective experience of happiness and life satisfaction, and the eudaimonic perspective, focusing on psychological functioning and self realization [3] and has been receiving increasing attention recently, is escalating the government schema $[11,12]$, and is becoming progressively valued as a key public health indicator. Governments in the worldwide are gradually recognizing the important role of improved mental well-being in aspect of making progress in society, reflecting human capital and mental health promotion initiatives [13]. Especially in Europe, research has increasingly addressed the assessment of mental well-being $[5,14]$.

Chronic heart failure (CHF) affects physical, psychological, and social aspects in individuals, gradually sets limits on physical activities [15] and leads to psychological and cognitive problems [16], which probably impact their quality of life and well-being. It is reported that more than half of CHF patients live with anxiety, about one third with depression, and nearly half with cognitive impairments [17-19]. However, these outcomes represent only one extreme of the wide-range spectrum of mental health. Whether the CHF patients' experience with negative aspects of mental health is also associated with mental well-being is still unclear, and there is rarely focusing on the mental well-being.
The Warwick-Edinburgh Mental Well-Being Scale (WEMWBS) was developed to evaluate positive mental health in the students and general population samples [10]. It has been found to be an appropriate instrument for assessing mental well-being in different samples: the general population [20-25]; teachers [26]; adolescents [6, $27,28]$; older people $[29,30]$; women with urinary incontinence [31, 32]; people experiencing mental health problems [33, 34]; caregivers of individuals with psychosis [35]; family caregivers of people with dementia [36]. It has been validated in Ireland [27], France [37], Norway [38], Pakistan [39, 40], China [41], Brazil [42], and Spain [43, 44]. The full Chinese version of the WEMWBS has been applied only among undergraduate nursing trainees [41]. Therefore, it is necessary to determine whether the scale may also be used in other populations. There are two versions of WEMWBS- a full version with 14 items and a short version with 7 items of the scale (SWEMWBS). Whether the SWEMWBS shows similar properties to the WEMWBS has yet to be explored [45]. Meanwhile, the short version presents a more restricted definition of mental well-being as it mainly encompasses hedonic items [38]. Therefore, we adopted the 14-item version to monitor mental well-being in CHF patients, as an important virtue of the WEMWBS has been its integrated brief and plentiful description of positive mental well-being.

In this study, we evaluated the psychometric properties of the WEMWBS among CHF patients applying the Chinese version of Warwick-Edinburgh Mental Well-Being Scale (C-WEMWBS) [41]. This was the first time for the C-WEMWBS to be applied in hospitalized CHF patients in China.

\section{Methods}

\section{Warwick-Edinburgh mental well-being scale}

The WEMWBS uses a five-point Likert scale; it contains 14 items, and each item ranges from 1 (none of the time) to 5 (all of the time). The total WEMWBS score ranges from 14 to 70 by totaling the 14 item scores. The higher the overall score, the greater is the level of mental well-being in general population group [10]. The scale assesses psychological functioning (e.g, clear thinking, positive energy, self-acceptance, and competence), positive effect (e.g., cheerfulness, feelings of optimism, and relaxation), and interpersonal relationships [10]. In the United Kingdom, the original WEMWBS has shown good psychometric properties with a single-factor hypothesis, supported by confirmatory factor analysis after allowing for correlation among some of the residuals [10].

The cross-cultural adaptation of WEMWBS into Chinese contained forward and backward translations with assessment of its cultural equivalence, clarity, and initiatory validation which showed high internal consistency 
reliability, test-retest reliability and preliminary construct validity [41].

\section{Additional measure}

We used an additional measure to test concurrently the validity of the C-WEMWBS. In the present study, all the measures were self-administered. The five-item World Health Organization Well-Being Index (WHO-5) [46] is a scale that evaluates general well-being over the previous 2 weeks. Each item ranges from 0 (at no time) to 5 (all of the time), with the total score ranging from 0 to 25. A total score of under 13 or a score equal to or less than 1 for any item indicates poor well-being or mood problems [47]. The Cronbach alpha was .85 in the current sample.

The present study was carried out in accordance with the ethical standards of the institutional research committee of the Second Affiliated Hospital of Wenzhou Medical University and with the 1964 Declaration of Helsinki and its later amendments or comparable ethical standards.

\section{Participants}

In this study, participants were recruited into the study from a teaching hospital and clinical center in Wenzhou, Zhejiang Province, China with convenience sampling. Patients with primary diagnosis of CHF were included when they met the following criterion: (1) could express themselves clearly, (2) aged over 18, (3) with New York Heart Association (NYHA) [48] functional class II to IV, (4) without addiction to smoking or alcohol, (5) not using antidepressants or anxiolytics, (6) without receiving permanent pacemaker, heart transplant or an implantable cardioverter defibrillator. We excluded the following participants: (1) concurrent inclusion in a study requiring additional visits to research health-care personnel; (2) having received an invasive intervention within the previous 6 months or having one planned during the following 3 months; (3) or ongoing evaluation for heart transplantation.

\section{Data collection}

In this study, we adopted a descriptive, cross-sectional design and aimed to recruit the amount of participants based on a well-accepted minimum of 10 individuals per questionnaire item [43] and less than the maximum of 25 [49]. We collected our data from July 2016 to July 2017. All the participants signed an informed consent form to take part. At the first stage, the structured questionnaire about the patients' general condition, together with the C-WEMWBS administered by a trained interviewer in a quiet, private room. The participants were asked by a registered physician if they had ever been diagnosed for other diseases, such as diabetes mellitus, hypertension, chronic lung disease, coronary heart disease, arthritis, and stroke, for more than 1 month. Clinical characteristics, such as left ventricular ejection fraction (LVEF) and NYHA classes of the participants, were retrieved from medical records. At the second stage, 35 participants who expressed interest in participating at former stage with health condition expecting steady were selected to evaluate a test-retest reliability analysis. These participants were invited and informed that the repeated questionnaire administration was for a test-retest reliability analysis. The participants completed the 30-item questionnaire with C-WEMWBS that had been embedded in (30-item questionnaire was extracted from the former questionnaire with complete scale of C-WEMWBS to avoid stereotyped image as to capture actual test-retest reliability result) when the patients with CHF visited the outpatient for follow-up in the following 2 weeks.

\section{Data analysis}

We used EpiData 3.1 software (EpiData Association, Odense, Denmark) for double entry and data management. We employed Amos version 17.0 software (Statistics Solutions, Clearwater, FL, USA) and SPSS version 19.0 (IBM Corp., Armonk, NY, USA) for statistical analysis.

We computed descriptive statistics and frequencies for the demographic variables and total scores with the CWEMWBS. Kolmogorov-Smirnov test was used to check the assumption and normality for the C-WEMWBS scores. We also sought ceiling and floor effects in the response distribution. Associations between C-WEMWBS scores and participant characteristics were evaluated using independent sample $t$ tests and one-way analysis of variance. Multiple comparison between the groups was performed using Student-Newman-Keuls method.

We used confirmatory factor analysis and exploratory factor analysis to evaluate the internal structure of the scale. Factor analysis with principal component analysis and varimax rotation were undertaken to assess the construct validity of the C-WEMWBS. Prior to principal component analysis, we evaluated the applicability of the scale with the following standards: a total Kaiser-Meyer-Olkin (KMO) measure of 0.7 or more and a statistically significant Bartlett's test of sphericity $(P<.05)$ correlation coefficient $>0.4$ for all variables. The number of components to be retained was determined by eigenvalues $>1$, the amount of variance explained, Cattell's scree plot, reliability analysis, and the interpretability criterion.

We used the Cronbach alpha coefficient to estimate internal consistency, item-total correlations, and reliability [50] of the C-WEMWBS in our sample; a value of .70 or more was considered acceptable [51]. The contents would be included if they had a factor loading of 0.4 . 
Item-total correlations were computed using the Pearson product-moment correlation coefficient. We evaluated test-retest reliability as the interclass correlation coefficient between the first and second administration of the C-WEMWBS.

We calculated both ceiling and floor effects of the 14 items of the scale; the scores were depicted as a histogram, and we inspected the distribution of the scores. We recorded the proportion of individuals with the highest and lowest potential scores. Values of $20 \%$ or greater were considered ceiling and floor effects. The values had to be below $20 \%$ to guarantee that the 14 items could detect a full range of possible responses in the sample and that response changes over time could be accurately evaluated [52].

Owing to the lack of a gold standard scale for well-being in China, we used the WHO-5 (a Chinese version is available) to estimate the construct validity. We calculated the Pearson correlation coefficient to assess the relationship between the WHO-5 and the C-WEMWBS. A $P$ value of $<.05$ was considered statistically significant.

\section{Results}

\section{Sample characteristics}

In all, 210 patients with CHF were initially invited to take part; of those, 201 agreed to participate, with a response rate with $95.7 \%(201 / 210)$. We excluded from the analyses participants who left more than three unanswered items on each questionnaire $(n=10)$, and the effective rate was $95.0 \%(191 / 201)$. The proportion of missing data for the C-WEMWBS was low (3.0\%); none of the items showed a greater likelihood of being left incomplete. The characteristics of the participants were as follows mean age (SD) was $73.79 \pm 11.93,82.2 \%$ lived with spouse, $68.6 \%$ received elementary education, $57.6 \%$ were self-perceived intermediate type of personality. Only $12.5 \%$ participants had more than three kinds of comorbidities even though $44.5 \%$ had total score of CCI higher than 3, while the percentage of NYHA III was 47.1, and 66.5\% had LVEF more than 40\%(Table 1, Additional file 1).

\section{Construct validity}

We conducted CFA to test the hypothesized single-factor structure of the C-WEMBWS, and the goodness of fit for a single confirmatory factor model was measured. Assuming no dependencies among the residuals, the initial model showed poor fit (comparative fit index $=0.87$, root mean square error of approximation $=0.14$ ). After correlated error terms were added in a stepwise fashion, adequate fit statistics were evident after 15 steps $\left(\chi^{2}=\right.$ $79.04, d f=62, \quad P=.07 ;$ comparative fit index $=.99$; Tucker-Lewis index $=.99$; goodness-of-fit index $=.95$; root mean square residual $=.03$; root mean square error of approximation $=.04$ ), as seen in Table 2. The goodness-of-fit results for a single-factor confirmatory model suggested an adequate one-dimensional structure [53].

\section{Descriptive statistics, floor and ceiling effects}

The mean \pm SD of C-WEMWBS scores were $42.31 \pm$ 11.85 (95\% confidence intervals, 40.62-44.01; skewness, 0.176; kurtosis, 0.350) with a median of 42(Fig. 1). One-Sample Kolmogorov-Smirnov Test did not display any significant deviation of the response from Normal distribution (Kolmogorov-Smirnov $\mathrm{Z}=1.280, p>0.05$ ). All the response categories were used by at least one person for all the scale items. Mean values for the individual items ranged from 2.23 (0.998) for item5 "I have energy to spare" to 4.18 (0.866) for item 12 "I've been feeling loved" (Table 2).

Among the participants, 31.4 and $41.9 \%$ responded "all of the time" for items 9 "I've been feeling close to other people" and 12 "I've been feeling loved", meanwhile, 22.5 and $26.7 \%$ responded "never" for items 13 "I've been interested in new things" and 5 "I've had energy to spare" $(n=191$; Table 3).

\section{Factor analysis of dimensionality with principal component analysis}

We subjected the C-WEMWBS responses to principal component analysis; the correlation matrix showed that all variables had at least one correlation coefficient greater than 0.4. The universal KMO measure was 0.938; individual KMO measures were all greater than 0.9 , which indicated appropriate classification. The Bartlett sphericity test was statistically significant $\left(\chi^{2}=2282.83\right.$, $d f=91, p<0.05)$, indicating that the data were suitable for factor analysis. Our principal component analysis identified two significant factors (Fig. 2) with eigenvalues greater than 1: together, they explained $69.12 \%$ of the total variance. The Cronbach alpha value, visual inspection of scree plot, eigenvalues, and interpretability criteria indicated that one component should be retained. The single-component solution explained $61.14 \%$ of the whole variance. The total score was obtained by summing all the items. The factor loadings of the rotated component matrix for all 14 items of the C-WEMWBS based on eigenvalues greater than 1 appear in Table 4 .

As shown in Table 4, factor loadings for each item ranged from .451 for item 12 "I've been feeling loved" to .902 for item 2 ("I feel useful"). The scree plot is presented in Fig. 2.

\section{Internal consistency and content validity}

The WEMWBS comprises 14 items. The internal reliability coefficient for the single-factor structure of 
Table 1 Demographic characteristics of a sample of CHF patients, who completed the C-WEMWBS $(n=191)$

\begin{tabular}{|c|c|c|c|c|c|}
\hline Characteristics & Variables & Frequency (\%) & Mean (SD) & $t / F(d f)$ & $P$ value \\
\hline \multirow[t]{2}{*}{ Gender } & Male & $117(61.3 \%)$ & $43.37(12.99)$ & $1.551(189)$ & 0.099 \\
\hline & Female & $74(38.7)$ & $40.65(9.64)$ & & \\
\hline \multirow[t]{3}{*}{ Age } & $\leq 60$ & $27(14.1 \%)$ & $50.67(10.86)$ & $14.560(2)$ & $2,0.000^{*}$ \\
\hline & $60-80$ & 103(53.9\%) & $43.17(11.22)$ & & \\
\hline & $\geq 80$ & $61(31.9)$ & $37.16(10.96)$ & & \\
\hline \multirow[t]{2}{*}{ Marriage } & With spouse & $157(82.2)$ & $43.51(11.31)$ & $2.819(44.73)$ & $0.007^{*}$ \\
\hline & Without spouse & $34(17.8)$ & $36.79(12.86)$ & & \\
\hline \multirow[t]{3}{*}{ Education level } & Elementary education & $131(68.6 \%)$ & $39.92(11.21)$ & $9.693(2)$ & $0.000^{*}$ \\
\hline & Secondary education & $48(25.1 \%)$ & $46.85(11.93)$ & & \\
\hline & College education & $12(6.3)$ & $50.25(10.27)$ & & \\
\hline \multirow[t]{3}{*}{ Comorbidities } & None & $66(34.6 \%)$ & $42.88(11.23)$ & $0.620(2)$ & $2,0.539$ \\
\hline & $1-3$ & $101(52.9 \%)$ & $41.50(12.35)$ & & \\
\hline & $>3$ & $24(12.5 \%)$ & 44.08(11.19) & & \\
\hline \multirow[t]{2}{*}{$\mathrm{CCl}$} & 1 & $104(54.5)$ & 44.65(10.79) & $3.008(171.135)$ & 0.003 \\
\hline & 2 & $79(44.5)$ & $39.52(12.50)$ & & \\
\hline \multirow[t]{3}{*}{ NYHA } & $\|$ & $57(29.8)$ & $46.04(12.02)$ & $5.542(2)$ & $2,0.005$ \\
\hline & III & $90(47.1)$ & $41.88(11.14)$ & & \\
\hline & IV & $44(23.0)$ & $38.39(11.88)$ & & \\
\hline \multirow[t]{3}{*}{ Personality } & Optimistic & $25(13.1)$ & $53.36(9.75)$ & $23.281(2)$ & $2,0.000^{*}$ \\
\hline & Pessimistic & $56(29.3)$ & 36.05(9.79) & & \\
\hline & Median & $110(57.6)$ & 42.99(11.26) & & \\
\hline \multirow[t]{2}{*}{ LVEF } & $\leq 40 \%$ & $64(33.5 \%)$ & $43.58(13.28)$ & 0.986(108.14) & 0.326 \\
\hline & $>40$ & $127(66.5 \%)$ & $41.68(11.06)$ & & \\
\hline
\end{tabular}

*:P $P 0.01$

the C-WEMWBS was .948, which was above the recommended lowest limit of .80 [47]. The corrected item correlations for the 14 items were greater than 0.4, thereby supporting the same construct for all items. The item-total statistics for all items appear in Table 5.

The Pearson correlation coefficients for each item-total pair ranged from .405 for item 12 "I've been feeling loved" ("I feel loved") to .872 for item 2 ("I feel useful"). These figures are comparable with those in one studied sample population [10], in which the coefficients ranged from $r=.50$ to $r=.75$.

\section{Construct validity: external consistency}

The Pearson correlation between the C-WEMWBS and WHO-5 was .79 $(P<.001, n=191)$ with a confidence interval of .728-.843. This result indicates a strong association between the C-WEMWBS and WHO-5.

\section{Test-retest reliability}

In all, 35 participants completed the retest questionnaires toward assessing the test-retest reliability over a 2 -week interval. The intraclass correlation coefficients showed a high test-retest reliability $(r=0.925, P<.001)$ for the C-WEMWBS, with a 95\% confidence interval of $.862-.966$.

\section{Discussion}

Building on the previous work of Dong et al. [41], who translated the 14-item WEMWBS and verified the reliability and validity of the scale in a sample of undergraduate nursing trainees, this research adds significant information about measurement model and invariance, reliability, and validity of the C-WEMWBS. The present study apply the C-WEMWBS in evaluating mental well-being in hospitalized patients with CHF. Outcomes showed that the scale may be favorable in predicting psychosocial results in CHF patients, which needs further study to prove. Furthermore, there are some connection between the results of mental well-being measured by the C-WEMWBS and demographic characteristics of patients, such as age, marital status, educational level, self-reported personality. And there are no difference between male patients and female patients which was consistent with the original study of evaluating the WEMWBS [10]. 
Table 2 Item-level statistics for responses on the C-WEMWBS in a sample of CHF patients $(n=191)$

\begin{tabular}{llll}
\hline Item & Content & 14-item version, no correlated errors & 14-item version with correlated errors \\
\hline C-WEMWBS-1 & I've been feeling optimistic about the future & 2.87 & 1.128 \\
C-WEMWBS-2 & I've been feeling useful & 2.80 & 1.106 \\
C-WEMWBS-3 & I've been feeling relaxed & 3.09 & .936 \\
C-WEMWBS-4 & I've been feeling interested in other people & 2.60 & 1.151 \\
C-WEMWBS-5 & I've had energy to spare & 2.23 & .998 \\
C-WEMWBS-6 & I've been dealing with problems well & 2.98 & 1.128 \\
C-WEMWBS-7 & I've been thinking clearly & 3.10 & 1.071 \\
C-WEMWBS-8 & I've been feeling good about myself & 2.89 & 1.107 \\
C-WEMWBS-9 & I've been feeling close to other people & 3.92 & .923 \\
C-WEMWBS-10 & I've been feeling confident & 2.91 & 1.772 \\
C-WEMWBS-11 & I've been able to make up my own mind about things & 3.19 & 1.081 \\
C-WEMWBS-12 & I've been feeling loved & 4.18 & .866 \\
C-WEMWBS-13 & I've been interested in new things & 2.44 & 1.136 \\
C-WEMWBS-14 & I've been feeling cheerful & 3.10 & 1.010 \\
\hline
\end{tabular}

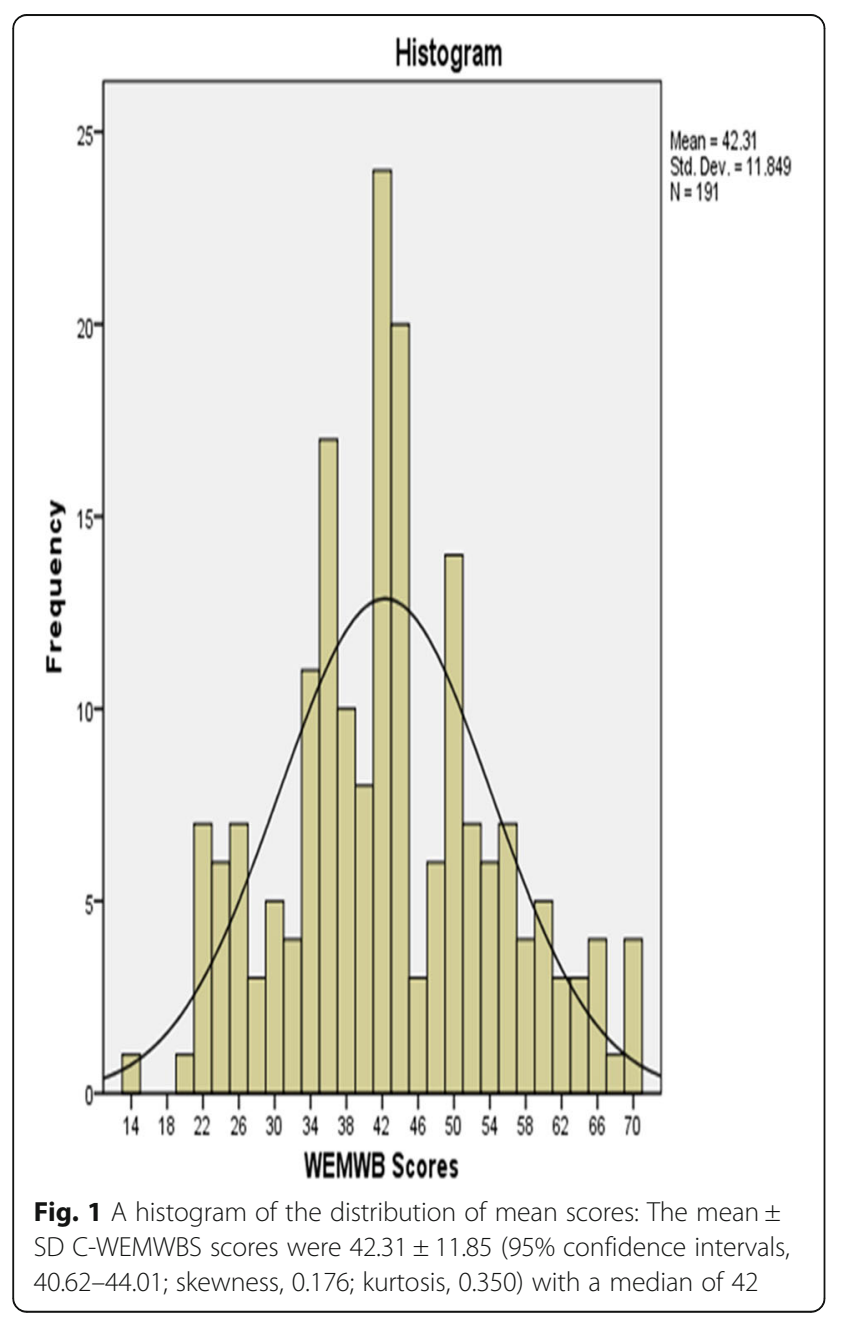

Studies on the WEMWBS in its original and later versions $[10,37-39,41-44]$ have demonstrated that it is a useful, reliable instrument for mental well-being, allowing population-level surveys and international comparisons to be performed. The validation of C-WEMWBS will provide the Chinese research society with an instrument prone to explore those elements with a positive impact on people's mental well-being that might help research to explore ways for empowering individuals, so that they can improve their own quality of life, helping us to evaluate important fields of people's emotional and social needs concept.

Similar to the results in the United Kingdom validation study of WEMWBS [10], the mean (SD) score for the C-WEMWBS in this study was 42.31 (11.85), which was lower than that for the WEMWBS in general population surveys around the world [24, 37, 38, 42, 44, 54, 55 ] and among women with urinary incontinence [31]. The C-WEMWBS scores in CHF patients were Normally distributed, which resembled the original scale [10]. Nonetheless, there may be some differences among different groups who could speaking Chinese [41, 56]. C-WEMWBS scores were skewed distributions in undergraduate nursing trainees [41], while the distribution of total scores of Chinese sample living Birmingham was normal with a slight tail towards the lower end [56]. These differences deserve further research.

Unlike with other generally used measuring instruments of mental health, we found that the C-WEMWBS showed that item-5 "I've had energy to spare", and item-13 "I've been interested in new things" showed floor effect, while item-9 "I've been feeling close to other people" and item-12 "I've been feeling loved" displayed ceiling effect. This was not consistent with those of 
Table 3 Percentage of floor and ceiling effects of C-WEMWBS $(n=191)$

\begin{tabular}{llll}
\hline Item & Content & Floor effect & Ceiling effect \\
\hline C-WEMWBS-1 & I've been feeling optimistic about the future & $23(12.0)$ & $15(7.9)$ \\
C-WEMWBS-2 & I've been feeling useful & $28(14.7)$ & $15(7.9)$ \\
C-WEMWBS-3 & I've been feeling relaxed & $8(4.2)$ & $13(6.8)$ \\
C-WEMWBS-4 & I've been feeling interested in other people & $31(16.2)$ & $15(7.9)$ \\
C-WEMWBS-5 & I've had energy to spare & $51(26.7)$ & 4(2.1) \\
C-WEMWBS-6 & I've been dealing with problems well & $17(8.9)$ & 23(12) \\
C-WEMWBS-7 & I've been thinking clearly & $9(4.7)$ & 23(12) \\
C-WEMWBS-8 & I've been feeling good about myself & $19(9.9)$ & 2(1.0) \\
C-WEMWBS-9 & I've been feeling close to other people & $28(14.7)$ & 17(8.9) \\
C-WEMWBS-10 & I've been feeling confident & $8(4.2)$ & 2(31.4) \\
C-WEMWBS-11 & I've been able to make up my own mind about things & $29(1.0)$ & 80(15.2) \\
C-WEMWBS-12 & I've been feeling loved & $43(22.5)$ & $10(5.9)$ \\
C-WEMWBS-13 & I've been interested in new things & $17(8.9)$ & $13(6.8)$ \\
C-WEMWBS-14 & I've been feeling cheerful & &
\end{tabular}

previous validation studies $[10,28,39,44,56]$. The results may have been due to the characteristics of the disease: CHF gradually sets limitations on physical activities and becomes a lifelong condition that eventually requires long-term treatment. Such individuals are short of energy and have no interest in new things. Item-9 and

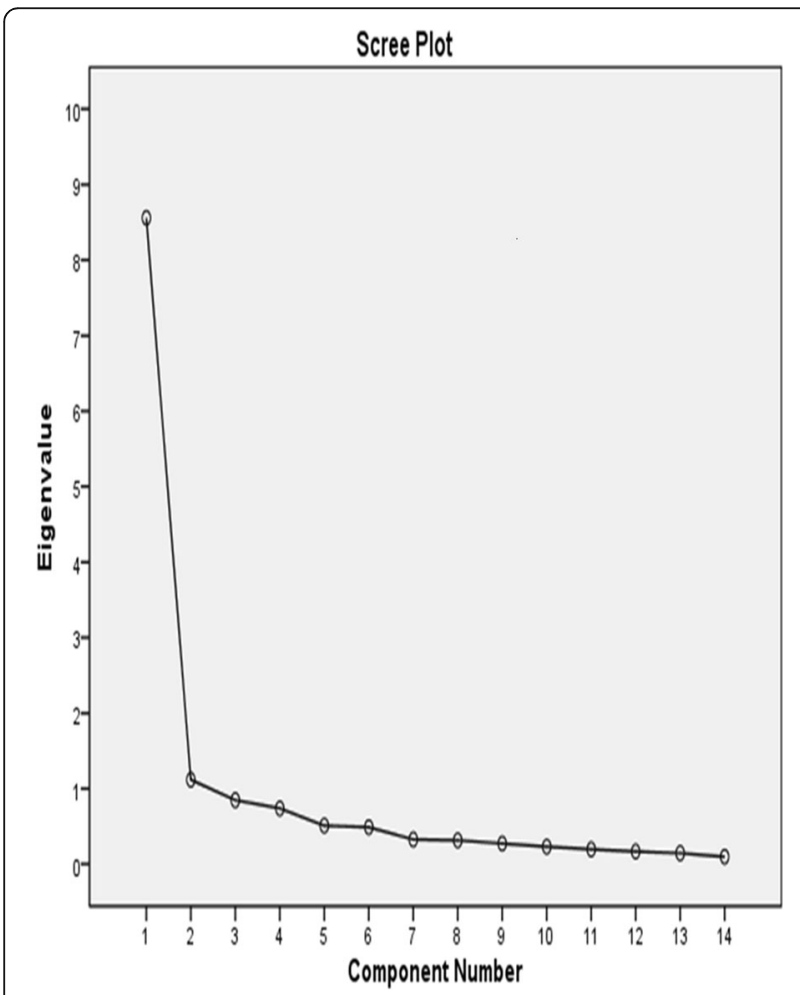

Fig. 2 Scree plot for 14-item WEMWBS. Our principal component analysis identified two significant factors with eigenvalues greater than 1 , which explained $69.12 \%$ of the total variance item-12 received a positive response: it was as high as 4.18. This could be explained that having a CHF patient in the family would make other family members try their best to provide the greatest help for those individuals owing to the limitations with daily life caused by CHF, they might even hire a housemaid to care for such people.

The C-WEMWBS had good reliability and validity for our sample similar to that of the original instrument. Notably, all the original Scottish [10], Chinese [41], and Spanish samples [44] fit a similar single-factor model, which suggests real deviation in the dominantly positive distribution of mental health traits. This result may reflect differences in the population samples-even in different settings. Therefore, further studies are needed to evaluate the C-WEMWBS in different clinical settings in China as well as with larger populations. Provided that there is no difference between original and Chinese version, potentially effective lines of study open regarding the causes like demographic characteristics and clinical features of these difference.

As in other studies conducted around the world, our analysis confirmed the unidimensional construct of the WEMWBS and its high internal consistency [10, 28, 39, 51, 57]. However, the factor structure was not as defined as in the original validation study [10] and other analyses $[28,39,51,57]$; this suggests multidimensionality emerging from the exploratory factor analysis. However, according to the researcher's viewpoint [43] that we could consider the solution as basically unidimensional if the ratio of the first to the second was over 4 . And in our analysis, the ratio of the first eigenvalue to the second one was close to 8 , and the spectrum of cross loading and the satisfactory additional variance explained by two 
Table 4 Factor loadings for the 14 items in the C-WEMWBS in a sample of CHF patients $(n=191)$

\begin{tabular}{lll}
\hline & Content & Factor loading \\
\cline { 2 - 3 } C-WEMWBS-1 & & .848 \\
C-WEMWBS-2 & I've been feeling optimistic about the future & .902 \\
C-WEMWBS-3 & I've been feeling useful & .830 \\
C-WEMWBS-4 & I've been feeling relaxed & .763 \\
C-WEMWBS-5 & I've been feeling interested in other people & .822 \\
C-WEMWBS-6 & I've had energy to spare & .881 \\
C-WEMWBS-7 & I've been dealing with problems well & .802 \\
C-WEMWBS-8 & I've been thinking clearly & .886 \\
C-WEMWBS-9 & I've been feeling good about myself & .622 \\
C-WEMWBS-10 & I've been feeling close to other people & .543 \\
C-WEMWBS-11 & I've been feeling confident & .804 \\
C-WEMWBS-12 & I've been able to make up my own mind about things & .451 \\
C-WEMWBS-13 & I've been feeling loved & .796 \\
C-WEMWBS-14 & I've been interested in new things & .844 \\
\hline
\end{tabular}

components (the second component was nearly 1)-together with the lack of a theoretical or explanatory foundation for the factor structure-indicated that a unidimensional model can be assumed.

There was some difference between the item-total correlations identified in the present study and the previous report [56] of Chinese people resident in the United Kingdom. Perhaps the differences are related to differences in the samples: our participants were Chinese-speaking CHF patients, the C-WEMWBS had been translated into
Chinese, and cultural differences exist between Eastern and Western countries. Further research needs to determine whether real differences in well-being or cultural issues affect such item-total correlations. Some of our participants indicated that certain words or phrases were difficult to understand and that the clinical setting for administering the questionnaire was a little unsettling for them.

We found that the C-WEMWBS showed a strong internal consistency reliability in this sample group: there was a high Cronbach alpha (0.948), and there were strong

Table 5 Unstandardized parameter estimates for items of the C-WEMWBS, and model fit estimates for four different onedimensional models for C-WEMWBS models without correlated error terms, three different one-dimensional models for C-WEMWBS models with correlated error terms $(n=191)$

\begin{tabular}{|c|c|c|c|c|c|}
\hline Content & $\begin{array}{l}\text { Scale Mean if Item } \\
\text { Deleted }\end{array}$ & $\begin{array}{l}\text { Scale Variance if } \\
\text { Item Deleted }\end{array}$ & $\begin{array}{l}\text { Corrected Item-Total } \\
\text { Correlation }\end{array}$ & $\begin{array}{l}\text { Squared Multiple } \\
\text { Correlation }\end{array}$ & $\begin{array}{l}\text { Cronbach's Alpha if } \\
\text { Item Deleted }\end{array}$ \\
\hline I've been feeling optimistic about the future & 39.45 & 119.175 & .810 & .779 & .935 \\
\hline I've been feeling useful & 39.51 & 118.220 & .872 & .846 & .934 \\
\hline I've been feeling relaxed & 39.22 & 123.141 & .789 & .656 & .937 \\
\hline I've been feeling interested in other people & 39.71 & 120.953 & .716 & .603 & .938 \\
\hline I've had energy to spare & 40.09 & 122.134 & .783 & .705 & .936 \\
\hline I've been dealing with problems well & 39.34 & 118.308 & .848 & .838 & .934 \\
\hline I've been thinking clearly & 39.21 & 121.345 & .759 & .785 & .937 \\
\hline I've been feeling good about myself & 39.42 & 118.530 & .857 & .766 & .934 \\
\hline I've been feeling close to other people & 38.39 & 127.724 & .567 & .538 & .942 \\
\hline I've been feeling confident & 39.41 & 118.264 & .493 & .294 & .951 \\
\hline $\begin{array}{l}\text { I've been able to make up my own mind about } \\
\text { things }\end{array}$ & 39.12 & 121.096 & .763 & .747 & .937 \\
\hline I've been feeling loved & 38.13 & 131.599 & .405 & .331 & .945 \\
\hline I've been interested in new things & 39.87 & 120.437 & .749 & .675 & .937 \\
\hline I've been feeling cheerful & 39.21 & 121.503 & .803 & .701 & .936 \\
\hline
\end{tabular}


internal positive correlations among the item-total scores (ranging from .405 to .872) [58]. The test-retest reliability correlation (intraclass correlation coefficient $=0.925$; $95 \%$ confidence interval, $0.862-0.966 ; n=35$ ) was unexpectedly high, indicating that the scale has acceptable stability [59].

The exploratory factor analysis results were consistent with the predicted scale structure, and all factor loadings were equal to or greater than .40 . Thus, the C-WEMWBS and original WEMWBS show similar reliability and validity for the whole-scale score. Accordingly, the C-WEMWBS was found to be a reliable, valid scale in our sample of CHF patients. We adopted the WHO-5 as a criterion to investigate the concurrent validity of the C-WEMWBS: we found a significant, positive correlation between the two scales. This result indicates that the C-WEMWBS has good criterion-related validity and suggests that WEMWBS measures a single underlying concept.

CFA showed that the C-WEMWBS has factorial validity. That together with principal component analysis revealing one significant factor with $59.45 \%$ of the total variance supports the hypothesized one-dimensional solution. The results from exploratory factor analysis and CFA were consistent, which indicates that the sample data in this study fitted the intrinsic hypothesis.

Our study has several limitations which deserve further research. Firstly, the size of the validation sample was relatively limited and the patients were recruited from a single centre. Secondly, there was short of a golden criterion questionnaire of mental well-being. So the WHO-5 was adopted to evaluate mental well-being to overcome this problem. The current research added evidence of a moderate positive association with WHO-5. Therefore, even acknowledging that complete validity could not be established, the C-WEMWBS shows the resemblance in validity to the original version. Thirdly, the essence of the descriptive, cross-sectional design adopted by the study impeded the evaluation of questionnaire responsiveness. Therefore, it's necessary to search further evidence about the responsiveness of the C-WEMWBS in an appropriate longitudinal study. Finally, there was only one paper reporting Memorial University of Newfoundland Scale of Happiness in CHF patients [60]. In the following work, we will compare the two scales in the CHF patients to check whether there is any difference.

\section{Conclusions}

To the best of our knowledge, this study is the first attempt to validate the WEMWBS for estimating the mental well-being in a population of CHF patients; thus, our investigation underscores the importance of this scale among the limited number of validated psychometric instruments available. Our participants had lower well-being scores than those reported in general population surveys worldwide. The C-WEMWBS showed good reliability and validity among our participants: it appears to be a reliable, valid instrument for use among Chinese-speaking CHF patients. Further research with larger, more diverse samples is needed to verify the universality of the C-WEMWBS and to examine its applicability to populations with different health statuses.

\section{Additional file}

Additional file 1: The stastical data in the EXCEL incluses results for ANOVA's and their post-hoc tests. (XLS 27 kb)

\section{Abbreviations}

CHF: Chronic heart heart; C-WEMWBS: Chinese version of Warwick-Edinburgh Mental Well-Being Scale; WEMWBS: Warwick-Edinburgh Mental Well-Being Scale; WHO-5: The five-item World Health Organization Well-Being Index

\section{Acknowledgments}

We thank our colleagues of the Cardiac Departments of the Second Affiliated Hospital of Wenzhou Medical University for their help.

\section{Funding}

This work was supported by the Program of Wenzhou Science and Technology Bureau (Grant Number Y20160167) and the Yumiao Project of Second Affiliated Hospital of Wenzhou Medical University in 2017.

Availability of data and materials

All data generated or analyzed during this study are included in this published article.

\section{Authors' contributions}

AD and WG wrote the article. XZ completed the data analysis. WZ tabulated the data. The other authors collected case materials. All authors read and approved the final manuscript.

Ethics approval and consent to participate

The study was approved by the Ethics Committee of the Second Affiliated Hospital of Wenzhou Medical University (Wenzhou, China).

Consent for publication

Not applicable.

\section{Competing interests}

The authors declare that they have no competing interests.

\section{Publisher's Note}

Springer Nature remains neutral with regard to jurisdictional claims in published maps and institutional affiliations.

\section{Author details \\ ${ }^{1}$ Emergency Department, the Second Affiliated Hospital of Wenzhou Medical University, College West Road 109, 0577 Wenzhou, Zhejiang, People's Republic of China. ${ }^{2}$ Cardiac Department, the Second Affiliated Hospital of Wenzhou Medical University, College West Road 109, 0577 Wenzhou, Zhejiang, People's Republic of China. ${ }^{3}$ Chemoradiotherapy Department, the Second Affiliated Hospital of Wenzhou Medical University, College West Road 109, 0577 Wenzhou, Zhejiang, People's Republic of China. ${ }^{4}$ Hematology Department, the Second Affiliated Hospital of Wenzhou Medical University, College West Road 109, 0577 Wenzhou, Zhejiang, People's Republic of China.}

Received: 30 April 2018 Accepted: 13 March 2019

Published online: 29 March 2019

\section{References}

1. What is mental health? [https://www.who.int/features/factfiles/mental health/en/] 
2. Ruseski JE, Humphreys BR, Hallman K, Wicker P, Breuer C. Sport participation and subjective well-being: instrumental variable results from German survey data. J Phys Act Health. 2014;11:396-403.

3. Ryan RM, Deci EL. On happiness and human potentials: a review of research on hedonic and eudaimonic well-being. Annu Rev Psychol. 2001;52:141-66.

4. Keyes CL. Mental illness and/or mental health? Investigating axioms of the complete state model of health. J Consult Clin Psychol. 2005;73:539-48.

5. Nordentoft M. Prevention of suicide and attempted suicide in Denmark Epidemiological studies of suicide and interv ention studies in selected risk groups. Dan Med Bull. 2007;54:306-69.

6. Davoren MP, Fitzgerald E, Shiely F, Perry IJ. Positive mental health and wellbeing among a third level student population. PLoS One. 2013;8:e74921.

7. Keller EJ. Philosophy in medical education: a means of protecting mental health. Acad Psychiatry. 2014;38:409-13.

8. Keyes CL. Promoting and protecting mental health as flourishing: a complementary strategy for improving nationa I mental health. Am Psychol. 2007:62:95-108.

9. Levav I, Rutz W. The WHO World Health Report 2001 new understanding-new hope. Isr J Psychiatry Relat Sci. 2002;39:50-6.

10. Tennant R, Hiller L, Fishwick R, Platt S, Joseph S, Weich S, Parkinson J, Secker J, Stewart-Brown S. The Warwick-Edinburgh mental well-being scale (WEMWBS): development and UK validation. Health Qual Life Outcomes. 2007;5:63.

11. Herrman H, Saxena S, Moodie R, Herrman H, Saxena S, Moodie R. Promoting mental health: concepts, emerging evidence, practice: a report of the World Health Organization. Geneva World Health Organization: Department of Mental Health and Substance Abuse in collaboration with the Victorian Health Promotion Foundation and the University of Melbourne; 2005.

12. No health without mental health. A cross-government mental health outcomes strategy for people of all ages [https://assets.publishing.service. gov.uk/government/uploads/system/uploads/attachment_data/file/138253/ dh_124058.pdf].

13. Haver A, Akerjordet K, Caputi P, Furunes T, Magee C. Measuring mental well-being: a validation of the short Warwick-Edinburgh mental well-being scale in Norwegian and Swedish. Scand J Public Health. 2015:43:721-7.

14. Reid S. Mind, the mental health charity: improving maternal mental wellbeing. Perspect Public Health. 2015:135:10-1.

15. Dong A, Chen S, Zhu L, Shi L, Cai Y, Zeng J, Guo W. The reliability and validity of Chinese version of SF36 v2 in aging patients with chronic heart failu re. Aging Clin Exp Res. 2017;29:685-93.

16. Chialà O, Vellone E, Klompstra L, Ortali GA, Strömberg A, Jaarsma T. Relationships between exercise capacity and anxiety, depression, and cognition in patients with heart failure. Heart Lung. 2018;47:465-70.

17. Almeida OP, Beer C, Lautenschlager NT, Arnolda L, Alfonso H, Flicker L. 2-year course of cognitive function and mood in adults with congestive heart failure and coronary a rtery disease: the heart-mind study. Int Psychogeriatr. 2012;24:38-47.

18. Vellone E, Fida R, D'Agostino F, Mottola A, Juarez-Vela R, Alvaro R, Riegel B. Self-care confidence may be the key: a cross-sectional study on the association between cognition and self-care behaviors in adults with heart failure. Int J Nurs Stud. 2015;52:1705-13.

19. Moser DK, Dracup K, Evangelista LS, Zambroski CH, Lennie TA, Chung ML, Doering LV, Westlake C, Heo S. Comparison of prevalence of symptoms of depression, anxiety, and hostility in elderly patients with $h$ eart failure, myocardial infarction, and a coronary artery bypass graft. Heart Lung. 2010;39:378-85.

20. Stranges S, Samaraweera PC, Taggart F, Kandala NB, Stewart-Brown S. Major health-related behaviours and mental well-being in the general population: the health survey fo $r$ England. BMJ Open. 2014;4:e005878.

21. Stewart-Brown S, Tennant A, Tennant R, Platt S, Parkinson J, Weich S. Internal construct validity of the Warwick-Edinburgh mental well-being scale (WEMWBS): a Rasch analys is using data from the Scottish health education population survey. Health Qual Life Outcomes. 2009;7:15.

22. Mitchell R. Is physical activity in natural environments better for mental health than physical activity in other environments? Soc Sci Med. 2013;91:130-4.

23. Phillips G, Bottomley C, Schmidt E, Tobi P, Lais S, Yu G, Lynch R, Lock K, Draper A, Moore D, et al. Well London Phase-1: results among adults of a cluster-randomised trial of a community engagement app roach to improving health behaviours and mental well-being in deprived inner-city neighbourhoods. J Epidemiol Community Health. 2014;68:606-14.

24. Powell J, Hamborg T, Stallard N, Burls A, McSorley J, Bennett K, Griffiths KM, Christensen $\mathrm{H}$. Effectiveness of a web-based cognitive-behavioral tool to improve mental well-being in the general po pulation: randomized controlled trial. J Med Internet Res. 2012;15:e2

25. Böhnke JR, Croudace TJ. Calibrating well-being, quality of life and common mental disorder items: psychometric epidemiology i n public mental health research. Br J Psychiatry. 2016;209:162-8.

26. Kidger J, Brockman R, Tilling K, Campbell R, Ford T, Araya R, King M, Gunnell D. Teachers' wellbeing and depressive symptoms, and associated risk factors: a large cross sectional study in English secondary schools. J Affect Disord. 2016;192:76-82.

27. McKay MT, Andretta JR. Evidence for the psychometric validity, internal consistency and measurement invariance of Warwick Edinburgh mental well-being scale scores in Scottish and Irish adolescents. Psychiatry Res. 2017:255:382-6.

28. Clarke A, Friede T, Putz R, Ashdown J, Martin S, Blake A, Adi Y, Parkinson J, Flynn P, Platt S, Stewart-Brown S. Warwick-Edinburgh mental well-being scale (WEMWBS): validated for teenage school students in England and Scotland. A mixed methods assessment. BMC Public Health. 2011;11:487.

29. Black SV, Cooper R, Martin KR, Brage S, Kuh D, Stafford M. Physical activity and mental well-being in a cohort aged 60-64 years. Am J Prev Med. 2015:49:172-80.

30. Cooper R, Stafford M, Hardy R, Aihie Sayer A, Ben-Shlomo Y, Cooper C, Craig L, Deary IJ, Gallacher J, McNeill G, et al. Physical capability and subsequent positive mental wellbeing in older people: findings from five HALCyon cohorts. Age (Dordr). 2014;36:445-56.

31. Abrams $P$, Smith AP, Cotterill N. The impact of urinary incontinence on health-related quality of life (HRQOL) in a real-world population of women aged 45-60 years: results from a survey in France, Germany, the UK and the USA. BJU Int. 2015;115:143-52.

32. Smith AP. Female urinary incontinence and wellbeing: results from a multinational survey. BMC Urol. 2016;16:22

33. Schrank B, Brownell T, Jakaite Z, Larkin C, Pesola F, Riches S, Tylee A, Slade M. Evaluation of a positive psychotherapy group intervention for people with psychosis: pilot randomised controlled trial. Epidemiol Psychiatr Sci. 2016;25:235-46.

34. Margrove KL, Heydinrych K, Secker J. Waiting list-controlled evaluation of a participatory arts course for people experiencing mental health problems. Perspect Public Health. 2013;133:28-35.

35. Sin J, Murrells T, Spain D, Norman I, Henderson C. Wellbeing, mental health knowledge and caregiving experiences of siblings of people with psychosis, c ompared to their peers and parents: an exploratory study. Soc Psychiatry Psychiatr Epidemiol. 2016;51:1247-55.

36. Orgeta V, Lo Sterzo E, Orrell M. Assessing mental well-being in family carers of people with dementia using the Warwick-Edinburgh mental well-being scale. Int Psychogeriatr. 2013;25:1443-51.

37. Trousselard M, Steiler D, Dutheil F, Claverie D, Canini F, Fenouillet F, Naughton G, Stewart-Brown S, Franck N. Validation of the WarwickEdinburgh mental well-being scale (WEMWBS) in French psychiatric and general populations. Psychiatry Res. 2016;245:282-90.

38. Smith ORF, Alves DE, Knapstad M, Haug E, Aaro LE. Measuring mental wellbeing in Norway: validation of the Warwick-Edinburgh mental well-being scale (WEMWBS). BMC Psychiatry. 2017;17:182.

39. Wagas A, Ahmad W, Haddad M, Taggart FM, Muhammad Z, Bukhari MH, Sami SA, Batool SM, Najeeb F, Hanif A, et al. Measuring the well-being of health care professionals in the Punjab: a psychometric evaluation of the Warwick-Edinburgh mental well-being scale in a Pakistani population. PeerJ. 2015;3:e1264.

40. Ahmad W, Taggart F, Shafique MS, Muzafar Y, Abidi S, Ghani N, Malik Z, Zahid T, Waqas A, Ghaffar N. Diet, exercise and mental-wellbeing of healthcare professionals (doctors, dentists and nurses) in Pakistan. PeerJ. 2015;3:e1250.

41. Dong A, Chen X, Zhu L, Shi L, Cai Y, Shi B, Shao L, Guo W. Translation and validation of a Chinese version of the Warwick-Edinburgh mental well-being scale with undergraduate nursing trainees. J Psychiatr Ment Health Nurs. 2016;23:554-60

42. Santos JJ, Costa TA, Guilherme JH, Silva WC, Abentroth LR, Krebs JA, Sotoriva P. Adaptation and cross-cultural validation of the Brazilian version of the Warwick-Edinburgh mental well-being scale. Rev Assoc Med Bras. 2015;61:209-14.

43. Lopez MA, Gabilondo A, Codony M, Garcia-Forero C, Vilagut G, Castellvi P, Ferrer M, Alonso J. Adaptation into Spanish of the Warwick-Edinburgh 
mental well-being scale (WEMWBS) and preliminary validation in a student sample. Qual Life Res. 2013;22:1099-104.

44. Castellvi P, Forero CG, Codony M, Vilagut G, Brugulat P, Medina A, Gabilondo A, Mompart A, Colom J, Tresserras R, et al. The Spanish version of the Warwick-Edinburgh mental well-being scale (WEMWBS) is valid for use in the general population. Qual Life Res. 2014;23:857-68.

45. Ng Fat L, Scholes S, Boniface S, Mindell J, Stewart-Brown S. Evaluating and establishing national norms for mental wellbeing using the short WarwickEdinburgh mental well-being scale (SWEMWBS): findings from the health survey for England. Qual Life Res. 2017;26:1129-44.

46. Chongwo E, Ssewanyana D, Nasambu C, Mwangala PN, Mwangi PM, Nyongesa MK, Newton CR, Abubakar A. Validation of a Swahili version of the World Health Organization 5-item well-being index among adults living with HIV and epilepsy in rural coastal Kenya. Glob Health Res Policy. 2018;3:26.

47. Ng SS, Lo AW, Leung TK, Chan FS, Wong AT, Lam RW, Tsang DK. Translation and validation of the Chinese version of the short Warwick-Edinburgh mental well-being scale for patients with mental illness in Hong Kong. East Asian Arch Psychiatry. 2014;24:3-9.

48. Rosenthal D, Chrisant MR, Edens E, Mahony L, Canter C, Colan S, Dubin A, Lamour J, Ross R, Shaddy R, et al. International society for heart and lung transplantation: practice guidelines for management of heart failure in children. J Heart Lung Transplant. 2004;23:1313-33.

49. Feldt $L S$, Ankenmann RD. Determining sample size for a test of the equality of alpha coefficients when the number of part-tests is small. Psychol Methods. 1999:4:366-77.

50. Bagby RM, Ryder AG, Schuller DR, Marshall MB. The Hamilton depression rating scale: has the gold standard become a lead weight? Am J Psychiatry. 2004;161:2163-77.

51. Stewart-Brown S, Tennant A, Tennant R, Platt S, Parkinson J, Weich S. Internal construct validity of the Warwick-Edinburgh mental well-being scale (WEMWBS): a Rasch analysis using data from the Scottish health education population survey. Health Qual Life Outcomes. 2009;7:15.

52. Bech P. Social functioning: should it become an endpoint in trials of antidepressants? CNS Drugs. 2005;19:313-24.

53. Williams $L$ J, O'Boyle EH. Ideal, nonideal, and no-marker variables: the confirmatory factor analysis (CFA) marker technique wor ks when it matters. J Appl Psychol. 2015;100:1579-602.

54. Phillips G, Bottomley C, Schmidt E, Tobi P, Lais S, Yu G, Lynch R, Lock K, Draper A, Moore D, et al. Well London Phase-1: results among adults of a cluster-randomised trial of a community engagement approach to improving health behaviours and mental well-being in deprived inner-city neighbourhoods. J Epidemiol Community Health. 2014;68:606-14.

55. Stranges S, Samaraweera PC, Taggart F, Kandala NB, Stewart-Brown S. Major health-related behaviours and mental well-being in the general population: the health survey for England. BMJ Open. 2014;4:e005878.

56. Taggart F, Friede T, Weich S, Clarke A, Johnson M, Stewart-Brown S. Cross cultural evaluation of the Warwick-Edinburgh mental well-being scale (WEMWBS) --a mixed methods study. Health Qual Life Outcomes. 2013;11:27.

57. Stochl J, Jones PB, Croudace TJ. Mokken scale analysis of mental health and well-being questionnaire item responses: a non-parametric IRT method in empirical research for applied health researchers. BMC Med Res Methodol. 2012;12:74.

58. Westen D, Rosenthal R. Improving construct validity: Cronbach, Meehl, and Neurath's ship. Psychol Assess. 2005;17:409-12.

59. Li T, Ma L, Mao C. The Validation and Reliability of the Chinese Version of the Speech Handicap Index for Patients With Oral and Oropharyngeal Cancer. J Voice. 2016;30:247 e223-231.

60. Zhao HX, Yuan Y, Chen CY. Effects of mindfulness - based stress reduction training on negative emotions in elderly patients with chronic heart failure. Chin J Mod Nurs. 2018:19:2315-2318.

Ready to submit your research? Choose BMC and benefit from:

- fast, convenient online submission

- thorough peer review by experienced researchers in your field

- rapid publication on acceptance

- support for research data, including large and complex data types

- gold Open Access which fosters wider collaboration and increased citations

- maximum visibility for your research: over $100 \mathrm{M}$ website views per year

At BMC, research is always in progress.

Learn more biomedcentral.com/submissions 